\title{
ANÁLISE DO FILME TECNOLOGIA E INTERNET: Uma reflexão psicológica sobre dependência à luz do filme "Her" \\ DOI: 10.22289/2446-922X.V4N3A1
}

\author{
Andressa Caroline Dornelas Ruas ${ }^{1}$ \\ Vania Cristine de Oliveira
}

\section{RESUMO}

Esse trabalho é referente à uma análise de filme, contextualizando os seguintes pontos: impacto que a internet e a tecnologia têm sobre o ser humano; sua relação negativa com a falta de interação e habilidades sociais e como a dependência tecnológica pode afetar as relações afetivas e sociais; sobre o seu avanço devastador e influente, modificando totalmente o mundo atual e como vai contribuir para o futuro. Para a realização desta análise foi utilizado o filme 'HER' (ELA)-lançado em fevereiro de 2014, com o gênero drama, romance e ficção cientifica-, bem como artigos do Google acadêmico, Portal Intercom, Scielo e o livro 'Dependência de internet: Manual e Guia de Avaliação e Tratamento' (obra escrita em 2011, com o objetivo de refletir acerca das influências psicológicas negativas oriundas dos avanços da tecnologia). Ainda não há um diagnóstico estabelecido para a dependência tecnológica, mas é possível constatar o prejuízo que vem arcando com a vida de muitas pessoas. Esse novo fenômeno deve ser discutido, já que vem chamando atenção de profissionais da área da saúde devido ao seu grande impacto desfavorável na sociedade. Podemos concluir que o uso da tecnologia pode beneficiar se usado de forma moderada, enquanto o uso excessivo pode trazer sérios problemas incluindo 0 adoecimento mental.

Palavras-chave: Dependência tecnológica; Internet; Vício; Adoecimento psicológico.

\section{ABSTRACT}

This work refers to an analysis of a movie, contextualizing the impact that the internet and the technology have on the human being. Its negative relation with the lack of interaction and social abilities and how technological dependence can affect affective and social relationships. Over its devastating and influential advance, fully modifying the current world and how it will contribute to the future. In order to carry out this analysis the movie "HER" which was released in February of 2014 was used, with the genre of drama, romance and science fiction, as well as academic Google articles, Portal Intercom, Scielo and the book "Internet addiction: A handbook and guide to evaluation and treatment" work written in 2011, with the objective of reflecting on the negative psychological influences coming from the advances of the technology. There still isn't an established diagnosis for technological dependence, but it's possible to notice the damage that it has been bearing on the lives of many people. This new phenomenon must be discussed, for it

\footnotetext{
${ }^{1}$ Endereço eletrônico de contato: andressacdornelas@gmail.com

Recebido em 28/09/2018. Aprovado pelo conselho editorial para publicação em 16/11/2018.
} 
has been attracting the attention of professionals in the health area, due to its great unfavorable impact on society. We can conclude that if used moderately the use of technology can be beneficial, while the overuse can bring serious problems including mental illness.

Keywords: Technological dependence; Internet; Addiction; Psychological hoarding.

\section{INTRODUÇÃO}

A internet tornou-se uma ferramenta indispensável como fonte de comunicação por ser um facilitador na busca por informações e, juntamente com a tecnologia, compõe o principal mecanismo para o estabelecimento de contatos sociais. A transição da era moderna se faz presente através dos avanços tecnológicos que abrangem um processo de transformação social causando mudança no modo de agir, pensar e de relacionar (Kohn \& Moraes, 2007).

A tecnologia tem sua ascensão maior no século XXI, onde a informação e comunicação se tornam imprescindíveis para desenvolvimento social. Através dos instrumentos associados à internet como redes sociais, jogos eletrônicos, facebook, aplicativos de relacionamentos e plataformas, que se tornaram um mecanismo de uso abundante com grande elevação das redes digitais. No entanto, à medida que a sociedade se expõe gradualmente ao uso dos meios digitais, surge a dependência da conectividade tecnológica como precursor de adoecimentos, ocasionando o desencadeamento de síndromes diversas (Barros \& Roldão, 2017).

Segundo Kohn e Moraes (2007) os padrões sociais foram modificados com a chegada da era digital, configurando a política da acessibilidade pautada na facilidade de promover o desenvolvimento dos serviços, informações, comércio e políticas, em processo de transformação dos cenários culturais e sociais, onde o ser humano revoluciona seu modo de se relacionar e de interagir nos meios onde está inserido.

A interação social faz parte do ensinamento de base primária da civilização, ou seja, normas e regras culturais. Também está ligada às habilidades sociais, da qual ainda não existe um consenso exato para a sua definição, porém entende-se como comportamentos e relações com os demais. Trata-se de comportamentos padronizados para uma interação, onde estão associados ao modo de pensar, agir e falar, não permitindo uma relação negativa diante da sociedade (Terroso \& Argimon, 2016).

Com o avanço da internet e tecnologia nos dias atuais tais habilidades sociais sofrem um grande impacto, pois as pessoas estão deixando de lado os seus comportamentos culturais e se apegando a um mundo virtual, onde deixam de se relacionar socialmente com outras pessoas, abstendo-se de seus sentimentos e sensações, passando a ter uma zona de conforto monótona (Kohn \& Moraes, 2007).

São imensuráveis os estragos que se destacam nas relações sociais, profissionais e amorosas. Além disso, estes causam um grande desconforto diante da impossibilidade de 
conexão e acesso, dando um viés acerca da presença de prováveis perturbações das quais a internet se torna como uma espécie de refúgio.

Diante do exposto, uma reflexão foi suscitada acerca dos impactos causados pela internet e tecnologia e sua forma de afetar as relações sociais dos seres humanos, bem como até onde podem influenciar o modo de viver e qual a sua relação com o adoecimento mental.

Para contextualização, foi escolhido o filme 'HER'(ELA), que retrata de uma forma sucinta e realista sobre o avanço devastador da tecnologia e da internet em um futuro próximo. O filme ganha destaque por ter uma alta qualidade de som e imagem, chegando mais próximo ao real sofrimento trazido pelo vício e domínio da tecnologia avançada.

Esse trabalho foi realizado em forma de análise de filme, acrescido de artigos recentes e manuais para melhor aprofundamento e enriquecimento teórico, com o objetivo de refletir acerca das influências psicológicas negativas oriundas dos avanços da tecnologia.

\section{2 ‘HER’ (ELA) E UMA VISÃO PSICOLÓGICA REFLEXIVA}

O filme 'Her' (Ela), lançado no dia 14 de fevereiro de 2013 com a duração de 02h e 06min, foi escrito e dirigido por Spike Jonze. O personagem principal trata-se de Theodore Twombly, atuado por Joaquim Phoenix.

A trama do filme retrata uma vida futura, onde os tempos mudaram e a tecnologia avançou de modo a proporcionar a comodidade e facilidade ao cotidiano das pessoas, que por sua vez tornaram-se sujeitos solitários, carentes, infelizes, distanciados da realidade das relações humanamente calorosas, passíveis ao conforto abusivo e também prejudicial dessa ferramenta.

O personagem principal vivencia um momento de crise devido ao processo recente de separação de sua esposa Catharine, em um casamento de dois anos que se findou em um término indesejado, insuportável e não superado por ele, que não conseguiu nem ao menos concluir a documentação do divórcio.

Theodore Twombly é um homem jovem que apresenta falta de habilidade social, solitário e melancólico. Ele se refugia entre as lembranças do passado e as experiências vividas diariamente. O personagem principal leva uma rotina automática e sem mudanças significativas em suas atividades, limita-se ao trajeto da casa para o trabalho e vice-versa, se esquivando de sensações afetivas como relações amorosas e sociais em seu dia-a-dia devido ao misto de emoções e sentimentos indefinidos, com os quais ele não sabe lidar.

Apesar dessa indefinição e esquiva, Theodore é funcionário de um site e trabalha como escritor de cartas, descrevendo as mais lindas histórias sem ao menos tê-las vivido. É contratado para auxiliar aquelas pessoas que desejam se expressar para alguém, mas não sabem como fazê-lo. 
No decorrer desta rotina, o personagem se depara com um novo sistema operacional que oferta uma inteligência artificial e voz humanizada, habilidades e eficiência programada para auxilio, simulando um trabalho humano de forma tão perfeita que se assemelhe à uma identidade pessoal e não a uma máquina. Nesta tentativa de semelhança, o sistema dispõe da opção de voz feminina ou masculina, que é escolhida por Theodore e apadrinhada pelo nome de Samantha. Esta o auxilia em seus afazeres, cuida de sua agenda, contribui em suas escolhas e passa a fazer parte de sua vida, participando de maneira aprofundada dos seus laços afetivos e sendo a companhia perfeita.

Diante do contexto, é possível refletir acercado fruto da globalização que gera o conflito do homem com a máquina, uma vez que fusão aliciada entre ambos é tão completa, que se torna dificultoso imaginar uma interação humana sem que haja a intermediação de um sistema virtual e da tecnologia.

Além da preocupante posição passiva e egoísta da pessoa que se sujeita à uma troca irreal, fantasiosa e limitada de uma relação sem passado ou futuro, que sacrifica uma intimidade e preserva $o$ isolamento nessa transição dos relacionamentos presenciais para os virtuais, a mensagem do filme explora as transformações nas relações familiares, sociais e afetuosa se sua banalização, em como a solidão do mundo pós-moderno, a substituição dos vínculos sentimentais e fraternos, e o afastamento de importantes figuras de referência como a função paternal e maternal.

O ser humano é um ser social que vive em sociedade e busca o equilíbrio nas relações humanas, no contato com o outro. Contudo, se ocorre o afastamento, a solidão se instala. Pessoas solitárias quase sempre escolhem atividades ou passatempos mais restritos, possuem crenças irracionais com expectativas não realistas, e se acomodam em situações confortativas, gerando uma dependência ou vícios como suporte emocional e auxílio diante desse vazio da solidão da modernidade.

A história do filme nos faz refletir sobre os caminhos seguidos pela humanidade, as transformações sofridas pelo avanço da tecnologia, combinado ao profundo vazio e falta de consciência, que por sua vez, abre campo e propicia o desenvolvimento de sérios adoecimentos psicológicos, como a depressão.

\section{O IMPACTO DA INTERNET NAS RELAÇÕES SOCIAIS: Uma discussão sobre o adoecimento mental diante da nova era tecnológica}

A nova era tecnológica traz uma mudança excessiva em seu novo aspecto, modernizado para a humanidade devido à facilitação dos seus dispositivos como computadores, tablets, 
telefones inteligentes e acessórios que facilitam o entretenimento, realizações de tarefas, pesquisas, auxílio no trabalho e até mesmo nas relações.

Como demonstrado no filme em questão, diante de circunstâncias difíceis e desconfortáveis-como luto, divórcio, desemprego, isolamento, rejeição-, onde o indivíduo não consegue lidar com suas experiências desagradáveis e que geram estados de angústia, consternação e vulnerabilidade emocional, o uso da internet pode ser enaltecido e o abuso dessa ferramenta tecnológica pode proporcionar uma espécie de válvula de escape, um aliciamento prazeroso para o mundo fantasioso e fictício, pois se acredita que o mundo virtual é capaz de oferecer um deslumbramento e a falsa sensação de apoio e acolhimento, tornando-se uma fuga psicológica, que distrai e ajuda a fugir do real sentimento negativo, gerando alivio dos problemas e consequentemente o vício e dependência (Young \& Abreu, 2011).

A dependência da internet (ID), é definida como incapacidade de controlar o uso impulsivo da mesma, trazendo graves danos tanto para vida de quem se sujeita ao vício, quanto de pessoas próximas a ela. A dependência tecnológica pode ser entendida como um conjunto de todas as outras dependências comportamentais, pois ela possui elementos centrais como: irritabilidade, ansiedade, depressão, abstinência, alteração no humor dentre outros.

Por mais que essa dependência venha se destacando negativamente, ainda não foi nomeada exclusivamente no manual de Diagnostico de Transtornos Mentais $5^{\text {a }}$ edição (DSM-V), embora possa ainda ser classificada, uma vez que se trata de um tema atual e relevante, possibilitando assim novos estudos e pesquisas a respeito (Young \& Abreu, 2011).

O personagem principal do filme retrata bem as consequências emocionais do uso excessivo da internet, que engloba a incapacidade de se relacionar e de manter amizades, ocorrendo uma obsessão em estar conectado, comprometendo as relações interpessoais, substituindo suas figuras vitais de referência e vínculos (Sá, 2012).

Tal obsessão além de contribuir com isolamento, acarreta em prejuízos ao funcionamento em amplos aspectos: má alimentação, dificuldades em dormir, problemas visuais, além da baixaestima e o sentimento de inferioridade, contribuindo para o adoecimento psíquico. Contudo, considera-se importante ressaltar que a depressão, não é gerada pela internet e sim fomentada a partir de uma pré-disposição (Alves, 2014).

Sob uma perspectiva psicológica, a tecnologia pode ser o fio condutor da doença, que contribui ao adoecimento das pessoas fazendo com que o ser humano perca a capacidade de lidar com suas emoções e problemas do mundo real, se refugiando em meios tecnológicos.

Nesse sentido, apesar da insuficiência literária relacionada às práticas colaborativas no tratamento da DI, a Psicologia traz a sua contribuição diante da problemática a partir de técnicas como da abordagem em Terapia Cognitiva Comportamental (TCC), que é indicada para um tratamento eficaz com o intuito de investigar as cognições distorcidas, a fim de auxiliar e 
permitirão paciente a reavaliação e reconstrução das mesmas (Abreu, Goes, \& Chwartzmann, 2008).

Por trabalhar com técnicas específicas, relaxamentos e treinamento respiratório, a TCC pode proporcionar relevantes resultados, auxiliando no controle de lidar com as suas emoções e controlar os impulsos relacionados à internet, sendo método conceituado como eficaz no plano de recursos terapêuticos (Pujol, 2009).

Segundo Barros e Roldão (2017), com a utilização da tecnologia a serviço das demandas sociais e afetivas estão realizando profundas transformações na sociedade e nas relações humanas. Trazendo uma ligação negativa entre tecnologia, saúde mental e física do usuário. Neste sentido, refletimos que se trata de um verdadeiro descompasso social, levando o ser humano à mercê de toda essa tecnologia, reformulando a forma de viver, pensar, sentir e se comportar.

\section{CONCLUSÃO}

Encarar uma situação problemática pode ser difícil e doloroso. $\mathrm{Na}$ atualidade o mundo online permite que as pessoas transpareçam que estão bem-mesmo não estando-,apresentando uma aparência fantasiosa de uma vida ideal, contrastando o self real com o self ideal na Psicologia. Desta for, o uso exagerado da tecnologia está causando sérios problemas psicológicos, emocionais e comportamentais associados à depressão, que é um transtorno abrangente no adoecimento social do indivíduo.

O filme 'Her' nos traz esse contexto de uma forma relevante, mostrando o impacto que a internet e a tecnologia têm sobre a vida do ser humano e sua contribuição para o desequilíbrio psicológico e patológico. Também podemos enfatizar o quanto as pessoas estão deixando de viver presencialmente: por medos, angustias fobias sociais... Estes poderiam ser mais bem compreendidos e tratados com psicólogos, psiquiatras e/ou profissionais que compõem a área da saúde.

Através da psicologia como ciência e profissão, a dependência tecnológica é vista como um prejuízo da perda de autonomia, ocasionando um desconforto decorrente da incapacidade de comunicação diante da ausência de dispositivos eletrônicos. Devido a isso os seres humanos, tanto jovens quanto adultos, estão sujeitos ao isolamento e inúmeros prejuízos graças ao uso demasiado dos recursos da internet.

Torna-se válido ressaltara importância de discussões e estudos sobre esse assunto, por tratarse de um tema da atualidade e que vem silenciosamente contribuindo com os danos emocionais e psíquicos, para aqueles que estão sujeitos a esse tipo de dependência. A partir do momento em que a internet torna-se constante na vida cotidiana, corrompendo o comportamento e refletindo negativamente na saúde mental, é necessário procurar ajuda de um profissional, afim Rev. Psicol Saúde e Debate. Dez., 2018:4(3):1-7. 
de minimizar a potencialidade dos danos a serem causados e propiciar ações de prevenção diante da possibilidade do adoecimento causado pela dependência.

Dentro desse presente trabalho, apreendeu-se grande dificuldade na elaboração do conteúdo considerando a escassez de literatura, pesquisas e estudos empíricos relacionados à dependência da internet, dificultando a textualização do mesmo, sendo válido ponderar sobre a importância de maiores estudos sobre o tema e ainda sobre o desenvolvimento de pesquisas que abordem essa problemática.

Portanto, pressupõe-se que este trabalho se torna agregador ao meio cientifico contribuindo para uma melhor reflexão dos aspectos vinculados à incapacitação do sujeito a frente de sua dependência dentro da era tecnológica atual.

\section{REFERÊNCIAS}

Abreu, C. N., Goes, D. S., Vieira, A. \& Chwartzmann, F. Dependência de Internet. In: C.N. Abreu, H. Tavares; Cordás, T. A. Manual clínico dos transtornos do controle dos impulsos. Porto Alegre: Artmed, 2008. p. 137-153.

Jonze, S. (Diretor). (2013). Her. [Filme]. IMDb: Warner Bros Pictures.

Pujol, C. C., Alexandre, S., Sokolovsky, A. Karam, R. G. \& Spritzer, D. T. (2009). Dependência de Internet: perspectivas em terapia cognitivo-comportamental. Revista Brasileira de Psiquiatria, 31(2), 185-186.

SÁ, G. M. (2012). À frente do computador: a Internet enquanto produtora de dependência e isolamento. Revista da Faculdade de Letras da Universidade do Porto, 24, p. 133-147.

Terroso, L. B., \& Argimon, I. I. (2016). Dependência de internet e habilidades sociais para adolescentes. Estudos e pesquisas em psicologia, 16(1), 200-219.

Barros, B. M. C., \& Roldão, M. L. (2017). A sociedade em rede e as doenças emergentes: uma proposta baseada na utilização excessiva das tecnologias digitais. Revista Sociais e Humanas. 30(1), 21-38.

Yong, K. S., \& Abreu, C. N. (2011). Dependência de internet: manual e guia de avaliação e tratamento. Porto alegre: Artmed.

Kohn, K. \& Moraes, C. H. (2007). O impacto das novas tecnologias na sociedade:conceitos e características da Sociedade da Informação e da Sociedade Digital. 2007. Congresso Brasileiro de Ciências da Comunicação, Intercom - Sociedade Brasileira de Estudos Interdisciplinares da Comunicação, 30 (pp. -). Santos, SP 